\title{
Antibacterial activity of essential oil from Wedelia trilobata leaves against Propionibacterium granulosum
}

\author{
Nuttakorn Baisaeng ${ }^{\mathrm{a}, *}$, Rungthip Kawaree ${ }^{\mathrm{b}}$, Anthika Boonma ${ }^{\mathrm{a}}$, Jariya Sadnen ${ }^{\mathrm{a}}$, Sunisa Khamkaew ${ }^{\mathrm{a}}$, \\ Srikanjana Klayraung ${ }^{\mathrm{b}}$ \\ a School of Pharmaceutical Sciences, University of Phayao, Phayao 56000 Thailand \\ b Division of Biotechnology, Faculty of Science, Maejo University, Chiang Mai 50290 Thailand \\ *Corresponding author, e-mail: patchateeya@yahoo.com
}

Received 28 Jun 2017

Accepted 24 Oct 2017

\begin{abstract}
This study reports on the in vitro antibacterial activity of hydro-distilled essential oil from Wedelia trilobata (L.) Hitchc leaves against Propionibacterium granulosum. The percentage yield of this essential oil via hydrodistillation was $0.21 \pm 0.01 \%(\mathrm{v} / \mathrm{w})$. A total of 112 chemical components present in the essential oil from $W$. trilobata leaves representing $62 \%$ of the total oil were identified by gas chromatography-mass spectrometry. The main bioactive constituents were monoterpenes, $\alpha$-pinene (19.5\%), $\alpha$-phellandrene (7.4\%), limonene (3.6\%), oxazine (3.3\%), and $\beta$-pinene (3.1\%). This essential oil showed the moderate antioxidant capacity of 1,1-diphenyl-2-picrylhydrazyl (DPPH) compared to the trolox equivalent antioxidant capacity and gallic acid equivalent, and possessed anti-P. granulosum activity from the inhibition zone from the disc diffusion method. The minimum inhibitory concentration (MIC, $595 \pm 206 \mu \mathrm{g} / \mathrm{ml}$ ) and minimum bacterial concentration (MBC, $1191 \pm 413 \mu \mathrm{g} / \mathrm{ml}$ ) values of this essential oil were higher than the MIC $(1.30 \pm 0.37 \mu \mathrm{g} / \mathrm{ml})$ and MBC $(2.61 \pm 0.91 \mu \mathrm{g} / \mathrm{ml})$ values of commercial clindamycin gel and the MIC $(52 \pm 18 \mu \mathrm{g} / \mathrm{ml})$ and MBC $(104 \pm 36 \mu \mathrm{g} / \mathrm{ml})$ values of commercial benzoyl peroxide gel. The results provide new information on the hydro-distilled essential oil from $W$. trilobata leaves, which may be important for developing new alternative anti-acne products.
\end{abstract}

KEYWORDS: antioxidant, anti-acne products, acne vulgaris, clindamycin gel, benzoyl peroxide gel

\section{INTRODUCTION}

Wedelia trilobata (L.) Hitchc is an introduced, soil creeping, evergreen perennial herb belonging to the family Asteraceae (formerly Compositae). Its synonym is Silphium trilobatum. It is mostly distributed in the tropical and subtropical countries such as Central America, South America, and the Pacific Islands. This invasive species can also be found in Thailand. Over the past decades, it has been historically used as a traditional folk medicinal plant, such as anti-headache, antipyretic ${ }^{1}$, and to treat upper respiratory tract infection ${ }^{2}$. In addition, previous studies reported that the methanolic and ethanolic extracts of $W$. trilobata flowers and leaves exhibited antioxidant and antibacterial activities ${ }^{3}$. In particular, the bioactive compounds from ethanolic extract of $W$. trilobata leaves showed potential wound-healing properties ${ }^{4}$. Crude extracts from other parts of $W$. trilobata also showed antibacte- rial activity against some strains of Gram-positive bacteria (Bacillus cereus, Bacillus subtilis, Mycobacterium smegmatis, Staphylococcus aureus, Staphylococcus epidermidis), Gram-negative bacteria (Proteus vulgaris, Pseudomonas aeruginosa, Salmonella group C, Salmonella paratyphi, Shigella sonnei), and fungus (Aspergillus flavus, Aspergillus niger, Aspergillus nidulans, Aspergillus flaviceps, Fusarium solani, Fusarium oxysporum, Fusarium verticilloides $)^{5}$. Several previous studies showed that the essential oil (EO) obtained from the leaves of $W$. trilobata contains a large variety of terpenes ${ }^{6}$ and exhibits antioxidant activity and antibacterial activity against $B$. subtilis and $S$. aureus ${ }^{7}$. No previous study has been reported about the essential oil from $W$. trilobata leaves against $P$. granulosum because $P$. granulosum belongs to the normal human skin flora. However, $P$ granulosum possesses a pathogenic role in acne vulgaris and plays an important synergistic role in the inflammation with Propi- 
onibacterium acnes which converts sebum oils into free fatty acids that accumulate in the hair follicle, form comedones, and then induce inflammation. Somehow, although topical anti-acne products (clindamycin, erythromycin, azelaic acid, tetracycline, and doxycycline) can reduce both $P$. acnes and $P$. granulosum population and exert anti-inflammatory actions, they lack antioxidant activity ${ }^{8}$ and may cause common side effects such as drug resistance and dark spots on the skin. Alternative natural essential oils can act against $P$. granulosum with a good antioxidant activity and may possess the necessary key activities for effective acne treatment.

The present study, therefore, aimed at studying the in vitro antibacterial activity of essential oil from $W$. trilobata leaves against $P$. granulosum gels by disc diffusion technique and two-fold serial dilution method, and compare it to commercial benzoyl peroxide and clindamycin. This study was designed to extract essential oil from $W$. trilobata leaves by hydrodistillation. The biochemical composition of EO was identified by gas chromatographymass spectrometry (GC-MS). Antioxidant capacity of EO was assessed by the free radical scavenging, DPPH assay. The findings from this study may be valuable to further in-vivo studies for acne product development.

\section{MATERIALS AND METHODS}

\section{Solvents and chemicals}

2,2-Diphenyl-1-picrylhydrazyl (DPPH), the watersoluble analogue of vitamin E (Trolox), and gallic acid were obtained from Sigma-Aldrich Co., St. Louis (USA). Clindamycin gel (Clindalin gel, Union Drug Laboratories Ltd., Thailand) and 2.5\% benzoyl peroxide gel (Benzac, Laboratories Galderma, France) was purchased from the drug store. Brain heart infusion (BHI) broth was purchased from Titan Biotech Ltd. (India), and Tween 80 was purchased from Uniqema Ltd. (Belgium). All solvents were analytical grade and used without further purification.

\section{Collection of plant materials}

Fresh specimen of $W$. trilobata leaves was collected from the area in University of Phayao, Phayao, Thailand on May 2015. A voucher specimen of this plant was deposited in the herbarium of the School of Pharmaceutical Sciences, University of Phayao, Phayao, Thailand.

\section{Extraction of the essential oil}

The fresh leaves of $W$. trilobata were cleaned by distilled water and dried at room temperature. Then $100 \mathrm{~g}$ of $W$. trilobata leaves was distilled in water sing an all-glass Clevenger-type apparatus $(n=3)$. The obtained essential oil was dried over anhydrous $\mathrm{Na}_{2} \mathrm{SO}_{4}$ and measured for calculation of percentage yield. The oil was stored in an amber vial at $4{ }^{\circ} \mathrm{C}$ until analysis.

\section{GC-MS analysis}

The hydro-distilled essential oil from leaves of $W$. trilobata was analysed by GC-MS using Agilent 6890 gas chromatograph equipped with a full-scan Hewlett Packard 5973 mass-selective detector in the electron impact mode $(70 \mathrm{eV})$. Separation was achieved by using Helium as carrier gas $(1 \mathrm{ml} / \mathrm{min})$ with a fused silica capillary column (HP5-MSI) of $30 \mathrm{~m}$ length, $0.25 \mathrm{~mm}$ internal diameter, and $0.25 \mu \mathrm{m}$ film thickness. Injector and detector temperatures were $260^{\circ} \mathrm{C}$ and $280^{\circ} \mathrm{C}$, respectively; with oven temperature programmes: $3 \mathrm{~min}$ isothermal at $70^{\circ} \mathrm{C}$, then raised at $3{ }^{\circ} \mathrm{C} / \mathrm{min}$ to $188^{\circ} \mathrm{C}$, and $20^{\circ} \mathrm{C} / \mathrm{min}$ to $280^{\circ} \mathrm{C}(3 \mathrm{~min}$ isothermal). Diluted samples $1 / 1000$ in dichloromethane $(\mathrm{v} / \mathrm{v})$ of $1.0 \mu \mathrm{l}$ were injected manually in the splitless mode. The percentage of peaks area was used for obtaining quantitative data. The programmed-temperature Kováts retention indices (RI) were obtained by GCMS analysis of an aliquot of the volatile oil spiked with an $n$-alkanes mixture containing homologues from $n-\mathrm{C}_{9}$ to $n-\mathrm{C}_{20}$. Identification of the compounds was based on a comparison of their mass spectra database (WILEY\&NIST) and spectroscopic data.

\section{Antioxidant capacity analysis}

The antioxidant capacity (AOC) of the essential oil of $W$. trilobata leaves was analysed by using DPPH method adapted from Bhatnagar et $\mathrm{al}^{9}$. EO with different weights was added to $3 \mathrm{ml}$ of ethanolic DPPH $(60 \mu \mathrm{M})$ to obtain the final concentrations of $1.5,3.1,6.2$, and $12.5 \mathrm{mg} / \mathrm{ml}(n=3)$. The mixture was shaken vigorously for $20 \mathrm{~s}$ at ambient temperature and the decrease in the absorbance at $517 \mathrm{~nm}$ was measured in a 1-cm disposable cuvette after $0,5,10,15,20,25$, and 30 min using double beam UV-Vis recording spectrophotometer (JASCO V-630). The AOC was calculated as $\left(A_{\text {blank }}-\right.$ $\left.A_{\text {sample }}\right) / A_{\text {blank }}$, where $A_{\text {blank }}$ is the absorbance of the control reaction (containing all reagents except EO) and $A_{\text {sample }}$ is the absorbance of EO. Inhibition of antioxidant capacity at $50 \%\left(\mathrm{IC}_{50}\right)$ was calculated 
and compared with trolox equivalent antioxidant capacity (TEAC) and gallic acid equivalent (GAE) as reference standards.

\section{Bacterial strain identification}

P. granulosum (DSM 20700) was originally isolated from disposable specimen of acne lesion from Medicinal Centre, University of Phayao, Phayao, Thailand. This bacterial isolate was identified by the conventional method including microscopy examination, safranin staining protocol, catalase test, and indole test. The identification result was confirmed by $16 \mathrm{~S}$ ribosomal RNA gene sequencing and compared with nucleotide sequence of the GenBank database reference number 118646.1 . The stock culture of $P$. granulosum was preserved in brain heart infusion agar deep tubes kept in anaerobic jar in an oven at $37^{\circ} \mathrm{C}$ for $48 \mathrm{~h}$.

\section{Sensitivity of $P$ granulosum by disc diffusion}

The disc diffusion method was used to determine the inhibition zone of $P$ granulosum from EO of $W$. trilobata leaves ${ }^{10}$. Approximately $10^{6} \mathrm{CFU} / \mathrm{ml}$ of $P$. granulosum was seeded onto $20 \mathrm{ml}$ of BHI agar. Then $10 \mu \mathrm{l}$ of essential oil was aseptically impregnated onto $6 \mathrm{~mm}$ paper disc in one application and dried at room temperature for $30 \mathrm{~min}$. An empty disc was used as a negative control. Discs containing commercial $2.5 \%$ benzoyl peroxide gel as lipophilic standard compound and 1\% clindamycin gel as lyophobic standard compound were used as positive controls. The discs were then placed on the surface of the seeded agar. Then the plates were kept in anaerobic jar and incubated at $37^{\circ} \mathrm{C}$ for $48 \mathrm{~h}$. The sensitivity of $P$. granulosum was defined by measuring the diameter of the growth inhibition zone. Each sample was performed in triplicate.

\section{Confirmation of essential oil from W. trilobata leaves against $P$. granusolum}

Anti-P. granulosum activity of EO was confirmed by determining the minimum inhibitory concentration (MIC) and minimum bactericidal concentration (MBC) using a dilution broth method. The MIC and MBC values of EO were compared to commercial $2.5 \%$ benzoyl peroxide gel and $1 \%$ clindamycin gel. Tween 80 was used to stabilize the EO. All tests were investigated in BHI containing $1 \%$ glucose. A twofold dilution of EO and commercial 1\% clindamycin gel was prepared in test tubes at concentrations that ranged from $0.39-1000 \mu \mathrm{g} / \mathrm{ml}$, whereas commercial $2.5 \%$ benzoyl peroxide gel concentrations ranged from 7.9-2000 $\mu \mathrm{g} / \mathrm{ml}$. The culture of $P$. granulosum was prepared by incubating in BHI broth with $1 \%$ glucose for $72 \mathrm{~h}$ under anaerobic condition. The bacterial culture was then added to each tube to make a final concentration of approximately $10^{6} \mathrm{CFU} / \mathrm{ml}$. In each test, $P$ granulosum in BHI broth and $\mathrm{BHI}$ broth alone were used as a positive and negative growth control, respectively. All test tubes were then incubated in an anaerobic jar at $37^{\circ} \mathrm{C}$ for $72 \mathrm{~h}$ before determination of the MIC and MBC. The cell pellet at the bottom was used to indicate the bacterial growth. The MIC value was defined as the lowest concentration of essential oil at which the bacteria do not express visible growth. To determine the MBC value, $10 \mu \mathrm{l}$ of broth was transferred from each test tube and spotted onto BHI agar. The number of surviving $P$. granulosum was determined after incubated at $37^{\circ} \mathrm{C}$ under anaerobic conditions for $72 \mathrm{~h}$. The lowest concentration where no initial inoculum survived was defined as MBC value. Each experiment was performed in triplicate.

\section{Statistic analysis}

All determinations were carried out in triplicate and the results are given as means \pm standard deviation. The statistical analysis was performed by using oneway ANOVA for 3 samples comparison at a significance level of 0.05 .

\section{RESULTS AND DISCUSSION}

\section{Extraction of the essential oil and GC-MS analysis}

The hydrodistillation of $100 \mathrm{~g}$ fresh $W$. trilobata leaves yielded $0.21 \pm 0.01 \%(\mathrm{v} / \mathrm{w})$. This hydro-distilled EO is a clear light-yellow oil with a distinctive odour. The hydro-distilled EO was analysed by GC-MS, and the bioactive constituents were identified based on their retention time values compared to those reported in the mass spectra database (WILEY\&NIST) and spectroscopic data representing the Kováts RI. The GC-MS analysis of this hydro-distilled EO of $W$. trilobata indicated that the main bioactive constituents were monoterpenes, such as $\alpha$-pinene $(19.46 \pm 0.04 \%), \alpha$-phellandrene $(7.39 \pm 0.04 \%)$, limonene $(3.63 \pm 0.05 \%)$, oxazine $(3.34 \pm 0.03 \%)$, and $\beta$-pinene $(3.12 \pm 0.03 \%)$ (Table 1$)$. The percentage of most of the individual constituents present in essential oil of $W$. trilobata leaves was not significantly changed during the hydrodistillation $(p<0.05)$. The current results indicate that the essential oil of $W$. trilobata leaves contains compo- 
Table 1 Chemical constituents of hydro-distilled essential oil from $W$. trilobata leaves by GC-MS.

\begin{tabular}{lcrr}
$\begin{array}{l}\text { Chemical } \\
\text { compound }\end{array}$ & $\begin{array}{c}\text { Area } \\
(\%)\end{array}$ & $\begin{array}{c}\text { Retention } \\
\text { time }(\mathrm{m})\end{array}$ & \multicolumn{1}{c}{$\begin{array}{c}\text { Kováts } \\
\text { RI }\end{array}$} \\
\hline$\alpha$-pinene & $19.46 \pm 0.04$ & $4.15 \pm 0.01$ & $982 \pm 1$ \\
$\alpha$-phellandrene & $7.39 \pm 0.04$ & $5.81 \pm 0.01$ & $1003 \pm 1$ \\
limonene & $3.63 \pm 0.05$ & $6.39 \pm 0.01$ & $1029 \pm 1$ \\
oxazine & $3.34 \pm 0.03$ & $32.2 \pm 0.01$ & $1153 \pm 1$ \\
$\beta$-pinene & $3.12 \pm 0.03$ & $5.07 \pm 0.01$ & $964 \pm 1$ \\
$\gamma$-terpinene & $0.03 \pm 0.01$ & $7.41 \pm 0.01$ & $1060 \pm 1$ \\
$\alpha$-terpinolene & $0.03 \pm 0.01$ & $8.40 \pm 0.02$ & $1089 \pm 1$ \\
4-terpineol & $0.05 \pm 0.02$ & $11.89 \pm 0.02$ & $1177 \pm 2$ \\
aromadendrene & $4.02 \pm 0.01$ & $23.00 \pm 0.02$ & $1490 \pm 2$ \\
caryophyllene & $0.32 \pm 0.01$ & $20.54 \pm 0.01$ & $1419 \pm 1$ \\
caryophyllene & & & \\
\multicolumn{1}{c}{ oxide } & $0.92 \pm 0.01$ & $27.99 \pm 0.01$ & $1583 \pm 1$ \\
\hline
\end{tabular}

nents relatively similar to those of other Wedelia species that showed monoterpenes, such as $\alpha$ pinene, $\alpha$-phellandrene, limonene, and caryophyllene, as the major compounds ${ }^{6,11-14}$. The percentage difference of chemical components in essential oils may be due to different material resources, seasonal variation, and extraction methods.

\section{Antioxidant capacity analysis}

The scavenging of free radicals is one of the wellknown mechanisms by which antioxidants inhibit lipid oxidation ${ }^{14}$, and the scavenging activity on DPPH radicals has been widely used to determine the free radical scavenging activity of active compounds as antioxidant. The DPPH radical scavenging activity can be reduced by the hydrogen donating ability ${ }^{15}$. Hence the measurement of the comparative interoceptive ability of antioxidant EO from $W$. trilobata leaves by determining its ability to scavenge DPPH radical has been proposed. As a dosedependent manner, the increasing concentrations of hydro-distilled EO from $W$. trilobata leaves $\left(\mathrm{IC}_{50}=\right.$ $23.31 \pm 0.10 \mathrm{mg} / \mathrm{ml}$ ) was a trend towards increased antioxidant capacity with moderate antioxidant activity for a period of $30 \mathrm{~min}$ as shown in Fig. 1 compared to TEAC $\left(\mathrm{IC}_{50}=9.37 \pm 0.08 \mu \mathrm{g} / \mathrm{ml}\right)$ and $\mathrm{GAE}\left(\mathrm{IC}_{50}=5.73 \pm 0.04 \mu \mathrm{g} / \mathrm{ml}\right)$. This current result indicates that the essential oil of $W$. trilobata with moderate antioxidant activity contains $\alpha$-pinene as a major bioactive compound relatively similar to a previous study that also reported moderate antioxidant activities for the essential oil of Wedelia species and its main components (limonene and $\alpha$-pinene) compared to $\alpha$-tocopherol and limonene ${ }^{12}$.

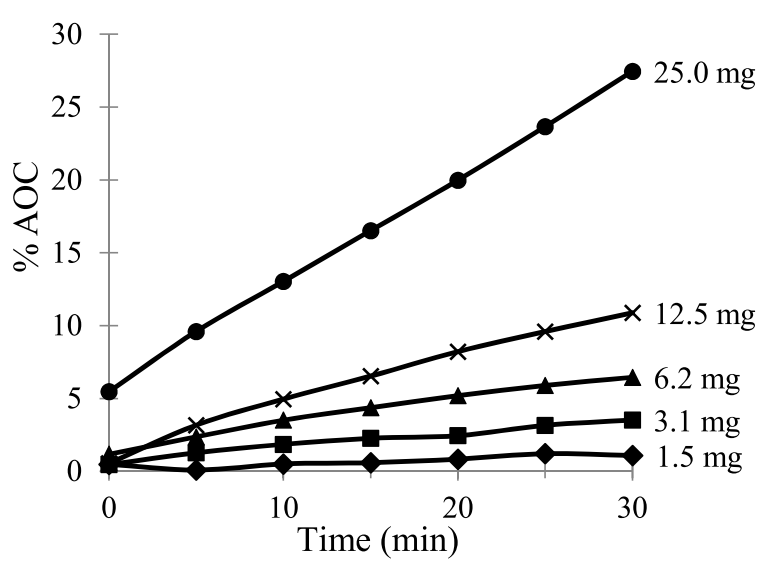

Fig. 1 The \% AOC of different concentrations from hydrodistilled essential oil from $W$. trilobata leaves.

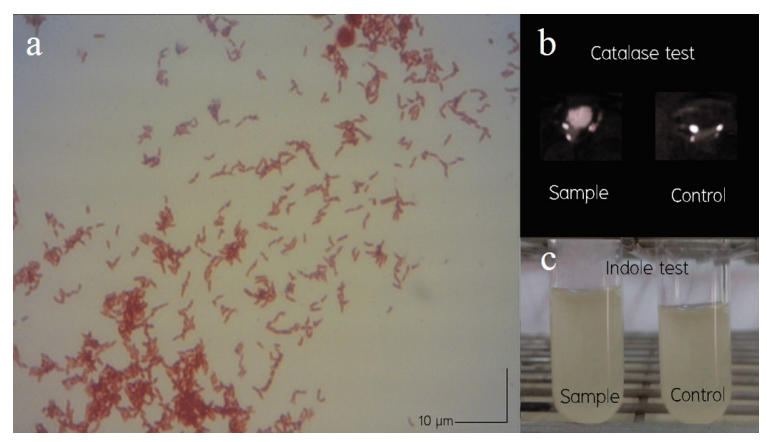

Fig. 2 (a) Gram stain and morphology of $P$ granulosum under light microscopy by $100 \times 10$-fold magnification, (b) positive result in catalase test, and (c) negative result in indole test.

\section{Bacterial strain identification}

The morphology and biochemical tests of isolated bacterial from disposable specimens were examined as preliminary identification. The results showed that the isolates of disposable specimen is Grampositive bacteria with a rod-shape bacterium because they counter-stained pink safranin as observed under light microscopy (Fig. 2a). The specimen (sample) also showed a positive result in catalase test after hydrogen peroxide was dropped into the specimen (Fig. 2b), whereas the indole test of both sample and control showed no cherry-red ring (Fig. 2c). From these results, the specimen could be $P$. granulosum or $P$. avidum. To distinguish between $P$. granulosum and $P$ avidum, the $16 \mathrm{~S}$ ribosomal RNA gene was sequenced, and the result showed 99\% homology with $P$. granulosum reference strain DSM 20700, and no gaps of the nucleotide sequence between the isolated specimen and the reference 


\begin{tabular}{|c|c|c|c|c|}
\hline $\begin{array}{l}\text { Score } \\
1354 \text { bits (733) }\end{array}$ & $\begin{array}{l}\text { Expect } \\
0.0\end{array}$ & $\begin{array}{l}\text { Identities } \\
735 / 736(99 \%)\end{array}$ & $\begin{array}{l}\text { Gaps } \\
0 / 736(0 \%)\end{array}$ & $\begin{array}{l}\text { Strand } \\
\text { Plus/Plus }\end{array}$ \\
\hline & & & & \\
\hline Sbjct 93 & & TCCCCACACTTTGGATA & 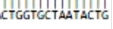 & \\
\hline Query 61 & gatatc & 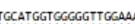 & itTGTCGATGGACTCG & 120 \\
\hline Sbjct 153 & GATAT & GCCATGGTCGGGTTGSOA & ITTGGCGATGGACCCG & 212 \\
\hline Query 121 & casce & TTGGTGGGGGAGTGGCCTAR & & 180 \\
\hline Sbict 213 & 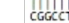 & 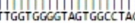 & 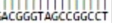 & 272 \\
\hline Query 181 & gacaces & САCATTRCGACTTGGGATAC & CTAACGGGaGGCAGCA & 240 \\
\hline Sbjct 273 & GaGaCe & 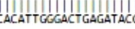 & 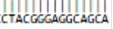 & 332 \\
\hline Query 241 & GTeces & $\angle A T G G G C C C A A G C C T C A T T$ & 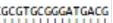 & 300 \\
\hline Sbjet 333 & Grocose $x$ & 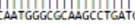 & extectastantace & 392 \\
\hline Query 301 & GCCTTS & АсCGCтTTCAGCAGGGACG & GACGGTACCTGCAGA & 360 \\
\hline Sbjct 393 & GeCT & CCGGCTтCACCAGGGaCe & AcGoracctocacas & 452 \\
\hline Query 361 & AGAaCG & CTACGTGCCAGCAGCCCCGG & SGGTGCGAGCGTTGTC & 420 \\
\hline Sbjct 453 & acalac & CTACG & GTCCGaccattatc & 512 \\
\hline Query 421 & CGGatr & GGGTCGAGGCGTT & ctrGa & 480 \\
\hline Sbjct 513 & cocat & 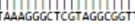 & 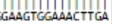 & 572 \\
\hline Query 481 & TGCTTS & TTCGATACGGGT & IIt & 540 \\
\hline Sbjct 573 & Fectt & 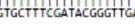 & frca & 632 \\
\hline Query 541 & ATTCC & GGAATCCGCAGATATCA, & 'AGTGCGCAGGCGGT & 600 \\
\hline Sbject 633 & ArTCC & 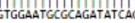 & GTGCGAacGCGG & 692 \\
\hline Query 601 & TCTCT & 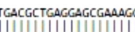 & АсаGсCTAGAтAC & 660 \\
\hline Sbjct 693 & & 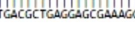 & & 752 \\
\hline Querv 661 & ecteg & GACI & & 720 \\
\hline Sbjct 753 & 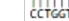 & AACCGTGGGTACT & ACCACGAATCTC & 812 \\
\hline Query 721 & TGece & & & \\
\hline Sbjct 813 & & & & \\
\hline
\end{tabular}

Fig. 3 Partial nucleotide sequence of 16 S ribosomal RNA of the isolated specimen of $P$ granulosum.

were found in the rage from 93-828 (Fig. 3). This isolated specimen could be considered as $P$. granulosum strain that can possess the pathogenic role in acne vulgaris and plays an important synergistic role in the inflammation with $P$. acnes. Although the EO extracted from the leaves of $W$. trilobata showed antioxidant activity and exhibited antibacterial activity against both Gram-positive and -negative bacteria $^{3-5}$, no anti-P. granulosum activity was reported. Hence sensitivity of $P$. granulosum by disc diffusion method was studied in the next step.

\section{Sensitivity of $P$. granulosum to the essential oil from $W$. trilobata}

The sensitivity of hydro-distilled EO from $W$. trilobata leaves against $P$. granulosum was qualitatively and quantitatively assessed by the presence of inhibition zones, MIC and MBC values (Table 2). Concerning disc diffusion method, clindamycin gel possessed the highest susceptibility against $P$. gra-

Table 2 Sensitivity of $P$ granulosum to hydro-distilled essential oil from $W$. trilobata leaves by disc diffusion and two-fold serial dilution methods.

\begin{tabular}{lccc}
\hline Subject & $\begin{array}{c}\text { Inhibition } \\
\text { zone }(\mathrm{mm})\end{array}$ & $\begin{array}{c}\text { MIC } \\
(\mu \mathrm{g} / \mathrm{ml})\end{array}$ & $\begin{array}{c}\text { MBC } \\
(\mu \mathrm{g} / \mathrm{ml})\end{array}$ \\
\hline empty disc & 0 & - & - \\
clindamycin gel & $53.5 \pm 3.1$ & $1.3 \pm 0.4$ & $2.6 \pm 0.9$ \\
benzoyl peroxide gel & $18.3 \pm 2.1$ & $52 \pm 18$ & $104 \pm 36$ \\
essential oil & $12.3 \pm 1.7$ & $595 \pm 206$ & $1191 \pm 413$ \\
\hline
\end{tabular}

nulosum, followed by benzoyl peroxide and hydrodistilled EO, whereas the empty disc did not affect the growth of $P$. granulosum as for the negative control. The results of MIC and MBC values showed that hydro-distilled EO (MIC $595 \pm 206$ and MBC $1191 \pm 413 \mu \mathrm{g} / \mathrm{ml}$ ) was higher than clindamycin (MIC $1.3 \pm 0.4$ and MBC $2.6 \pm 0.9 \mu \mathrm{g} / \mathrm{ml}$ ) and benzoyl peroxide gels (MIC $52 \pm 18$ and MBC $104 \pm 36 \mu \mathrm{g} / \mathrm{ml})$. This means the essential oil of $W$. trilobata leaves has lower anti-P. granulosum than clindamycin and benzoyl peroxide gels. Although clindamycin and benzoyl peroxide have a good efficacy against $P$. granulosum, they may induce side effects and oxidation reaction after application. To overcome the disadvantages of clindamycin and benzoyl peroxide, the hydro-distilled EO from $W$. trilobata leaves may decrease the side effects and oxidation reaction of clindamycin and benzoyl peroxide and give valuable information for the development of a new alternative anti-acne product with mild antioxidant activity. In addition, the synergistic effects of the diverse major and minor chemical components of essential oils from $W$. trilobata leaves should be further taken into consideration to account for the oil biological activity.

\section{CONCLUSIONS}

The hydro-distilled EO of $W$. trilobata leaves possesses antibacterial activity against $P$. granulosum with moderate antioxidant capacity compared to commercial clindamycin and benzoyl peroxide gels. This may be due to the synergistic effects of $\alpha$ pinene and other bioactive compounds in the oil. This present study suggests a possible alternative option from this oil for the development of new effective anti-acne products in the near future. However, the toxicological properties should be further studied in an in vivo model to support the information of this study.

Acknowledgements: This study was supported by School of Pharmaceutical Sciences, University of Phayao, Phayao, Thailand. The author wishes to gratefully thank Division of Biotechnology, Faculty of Science, Maejo University, Chiang Mai, Thailand for supporting laboratory equipment and useful advice.

\section{REFERENCES}

1. Lin SC, Lin CC, Yin YH, Shyuu SJ (1994) Hepatoprotective effects of Taiwan folk medicine: Wedelia chinensis on three hepatotoxin-induced hepatotoxicity. Am J Chin Med 22, 155-68.

2. Miles DH, Chittawong V, Payne AM, Hedin PA, Kokpol U (1990) Cotton boll weevil antifeedant activity and 
antifungal activity (Rhizoctonia solani and Pythium ultimum) of extracts of the stems of Wedelia biflora. J Agr Food Chem 38, 1591-4.

3. Balekar N, Nakpheng T, Srichana T (2014) Wedelia trilobata L.: a phytochemical and pharmacological review. Chiang Mai J Sci 41, 590-605.

4. Balekar N, Katkam NG, Nakpheng T, Jehtae K, Srichana T (2012) Evaluation of the wound healing potential of Wedelia trilobata (L.) leaves. $J$ Ethnopharmacol 141, 817-24.

5. Taddei A, Rosas-Romero AJ (1999) Antimicrobial activity of Wedelia trilobata crude extracts. Phytomedicine 6, 133-4.

6. Craveiro AA, Matos FJA, Alencar JW, Machado MIL, Krush A, Silva MGV (1993) Volatile constituents of two Wedelia species. J Essent Oil Res 5, 439-41.

7. Nirmal SA, Chavan MJ, Tambe VD, Jadhav RS, Ghogare PB, Bhalke RD, Girme AS (2005) Chemical composition and antimicrobial activity of essential oil of Wedelia trilobata leaves. Indian J Nat Prod 21, 33-5.

8. Musial W, Kubis A (2003) Preliminary assessment of alginic acid as a factor buffering triethanolamine interacting with artificial skin sebum. Eur J Pharm Biopharm 55, 237-40.

9. Bhatnagar AS, Prasanthkumar PK, Hemavathy J, Gopalakrishna AG (2009) Fatty acid composition, oxidative stability and radical scavenging activity of vegetable oil blends with coconut oil. $J$ Am Oil Chem Soc 86, 991-9.

10. Bauer AW, Kirby WMM, Sherris JC, Turck M (1966) Antibiotic susceptibility testing by a standardized single disk method. Am J Clin Pathol 45, 493-6.

11. Li D, Liang Z, Guo M, Zhou J, Yang X, Xu J (2012) Study on the chemical and extraction technology optimization of essential oil from Wedelia trilobata (L.) Hitchc. Afr J Biotechnol 11, 4513-7.

12. Dai J, Zhu L, Yang L, Qiu J (2013) Chemical composition, antioxidant and antimicrobial activities of essential oil from Wedelia prostrata. EXCLI $J$ 12, 479-90.

13. Silva CJ, Barbosa LCA, Demuner AJ, Montanari RM, Francino D, Meira RM, Souza AO (2012) Chemical composition and histochemistry of Sphagneticola trilobata essential oil. Rev Bras Farmacogn 22, 482-9.

14. Hatano T, Edamatsu R, Hiramatsu M, Mori A, Fujita Y, Yasuhara T, Yoshida T, Okuda T (1989) Effects of the interaction of tannins with coexisting substances. VI.: Effects of tannins and related polyphenols on superoxide anion radical and on 1,1-diphenyl-2-picrylhydrazyl radical. Chem Pharmaceut Bull 37, 2016-21.

15. Prasad NK, Divakar S, Shivamurthy GR, Aradhya SM (2005) Isolation of a free radical-scavenging antioxidant from water spinach (Ipomoea aquatica Forsk). J Sci Food Agr 85, 1461-8. 